\title{
Measurement of Local Heat Transfer Coefficients of Developing Flows Using IR-Thermography
}

\author{
by Marta Cortina Díaz, Hermann Woche, Jürgen Schmidt, Eckehard Specht
}

Institute of Fluid Dynamics and Thermodynamics, Otto-von-Guericke University, Universitätsplatz, 2, D-39106 Magdeburg, Germany

Tel. +49-3916718576, fax +49-3916712762

e-mail: marta.cortina@vst.uni-magdeburg.de

\begin{abstract}
The experimental determination of heat transfer coefficients has been intensively discussed in the literature. Infrared thermography offers an interesting possibility to analyze the heat transfer characteristics of fluid flow due to its high spatial and temporal resolution and non-invasive nature.

The present study describes the application of infrared thermography to determine the heat transfer coefficients of developing flows after a contraction or extension of the cross sectional area. Water and air are used as working fluids and a different experimental setup is employed in each case.
\end{abstract}

\section{Introduction}

The knowledge of fluid flow and heat transfer characteristics after crosssectional changes is essential for many practical applications. The inflow in heat exchangers is commonly linked with a contraction of the cross section, and rotatory kilns and drums or combustion chambers are only some examples of processes where an extension of the cross section occurs.

Different measurement methods can be applied to the determination of heat transfer coefficients of developing flows. Thermocouples positioned along the channel length are frequently used to obtain the temperature at discrete locations. Infrared thermography is applied here to scan the outer wall temperatures and hence, some of the disadvantages of the use of thermocouples can be avoided. One of the most remarkable advantage of the applied infrared measurement method is the possibility of the precise determination of minima and maxima of the heat transfer coefficient, especially for different operating conditions. This measurement method was already succesfully employed in, for example, [1-4].
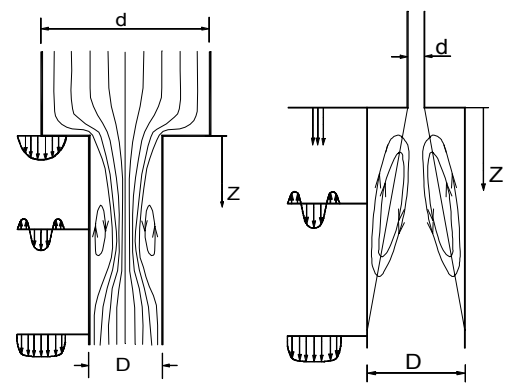

Fig. 1. Investigated phenomena

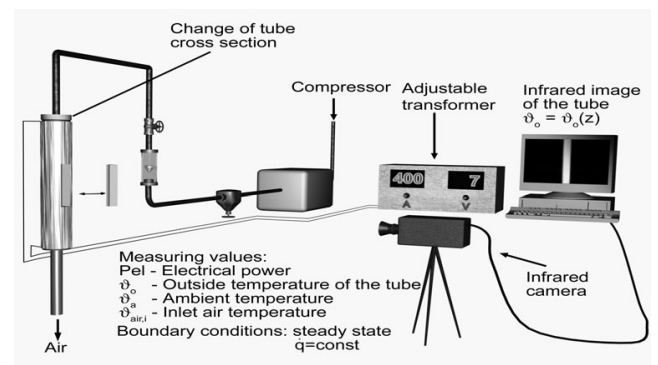

Fig. 2. Experimental setup for air 
The present study focuses on both contraction and extension of the cross sectional area, fig. 1. The Reynolds number ranges from 1000 to 100000 and the diameter ratio is systematically varied in order to investigate the influence of the geometrical parameters.

\section{Experimental Setup and Data Reduction}

Experimental measurements are carried out in two different experimental equipments depending on the test fluid used. In both apparatus the circular test sections, made of stainless steel, have an inner diameter of $29 \mathrm{~mm}$ and are electrically heated. In order to investigate the influence of the Prandtl number on the heat transfer characteristics, compressed air and distilled water are used as working fluids.

The volumetric flow rate of air is adjusted by a control valve and is varied from 0.2 to $300 \mathrm{~m}^{3} / \mathrm{h}$ using different rotameters, fig. 2. The inlet air temperature is set to $20^{\circ} \mathrm{C}$, which corresponds to a constant Prandtl number of 0.71 . On the other hand, distilled water flows in a closed loop, fig. 3. The water is degassed before measuring. Both Reynolds and Prandtl numbers at the inlet of the test section are maintained constant by adjusting volumetric flow and fluid temperature to a constant value. The inlet temperature of water is set by using a heat exchanger, which allows an accuracy up to $0.1 \mathrm{~K}$. The temperature is adjusted to $25.6^{\circ} \mathrm{C}$ and $44.1^{\circ} \mathrm{C}$, which correspond to Prandtl numbers of 6 and 4 . The electrical conductivity of water is experimentally verified. The fact that its value lies below $25 \mu \mathrm{S} / \mathrm{cm}$ allows to neglect the losses due to the current flowing through the water.

The test section is electrically heated. Thus constant heat fluxes up to $25 \mathrm{~kW} / \mathrm{m}^{2}$ can be achieved. An insulating jacket allows for the dampening of heat losses to the environment through natural convection and radiation within reasonable limits and so for the minimizing of their influence on the axial heat flux, fig. 4. An insulating thickness of $30 \mathrm{~mm}$ is selected and thus the heat losses are reduced in $80 \%$.

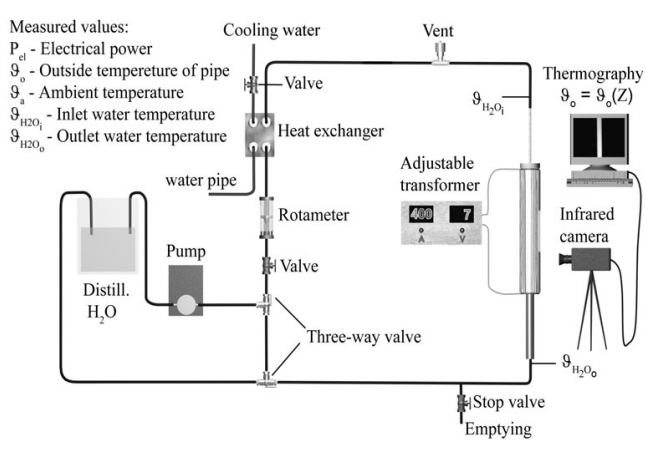

Fig. 3. Experimental setup for water

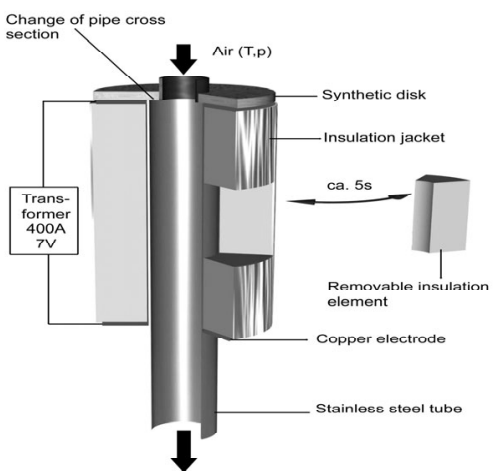

Fig. 4. Test section

The time spacing between consecutive measurements required to achive the steady state is determined by numerical simulations.

The maximal wall temperature is adjusted by the current so that the temperature of air does not exceed $200^{\circ} \mathrm{C}$. The difference between air and wall temperature lies between 60 and $140 \mathrm{~K}$ depending on the current. 
In the case of water and due to the higher heat transfer coefficients the wall temperature remains below $65^{\circ} \mathrm{C}$ and the above mentioned temperature difference lies between 2 and $14 \mathrm{~K}$.

Infrared thermography allows an accurate and contactless measurement of the channel outer wall temperature distribution. The data recording is performed by an AGEMA Thermovision 900 system with a measuring wavelength range of $8-12 \mu \mathrm{m}$. The infrared thermography provides high spatial and temporal resolution. The duct wall is coated with a special black lacquer to assure high emissivity and reduce the measuring error. This emissivity of the outer wall is measured as a function of the temperature and fit to a polynomial approximation. It can also be controlled between test series by comparing the temperatures read by the camera with those obtained using thermocouples positioned at discrete locations of the outer wall.

Once the steady state is reached, an axial segment of the annular insulating shell is removed for a short period of time (approx. $5 \mathrm{~s}$ ). The uncovered section of the channel is scanned and so the outer wall temperatures in the axial direction registered. The obtained temperature distribution constitutes the basis for the determination of the local heat transfer coefficients. Therefore, the channel length is divided into small, discrete sections $\Delta z$, fig. 5 . Assuming steady state, the heat transfer rate for the $\mathrm{j}^{\text {th }}$ section can be calculated as

$$
\dot{Q}_{j}=P_{e l, j}-\dot{Q}_{L, j}-\dot{Q}_{C, j} \text {, }
$$

where $P_{e l, j}$ is the electrical input power, $\dot{Q}_{L, j}$ is the heat loss to the environment and $Q_{C, j}$ represents the axial heat conduction in the wall.

The local heat transfer coefficient $\alpha_{j}^{*}$ is defined as

$$
\dot{Q}_{j}=\alpha_{j}^{*} \pi D \Delta z\left[\vartheta_{j}-\vartheta_{b u l k, j}\right]
$$

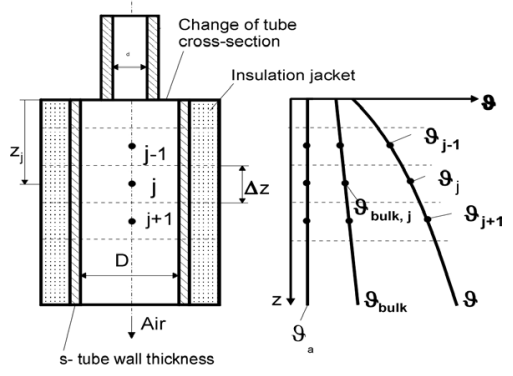

Fig. 5. Segmentation of the test section

where $\vartheta_{\text {bulk,j }}$ is the bulk fluid temperature, which results from an enthalpy balance for the jth section, and $\vartheta_{\mathrm{j}}$ is the inner wall temperature, which can be approximated to the outer wall temperature, $\vartheta_{\text {out,j }}$ For higher precision, $\vartheta_{\mathrm{j}}$ can be calculated using the analytical solution for steady state heat conduction with a heat source. The discrepancy for air lie between 0.05 and $0.3 \mathrm{~K}$, fig. 6 .

Taking both equations into account, the heat transfer coefficient and the corresponding Nusselt number can be calculated as

$$
\begin{aligned}
& \alpha_{j}^{*}=\frac{P_{e l, j}-\dot{Q}_{L, j}-\dot{Q}_{C, j}}{\pi D \Delta z\left[\vartheta_{j}-\vartheta_{\text {bulk,j }}\right]}, \\
& \mathrm{Nu}_{j}^{*}=\frac{\alpha_{j} \mathrm{D}}{\lambda_{\text {air }}\left(\vartheta_{\text {bul }, \mathrm{j}}\right)} .
\end{aligned}
$$

The electrical input power is calculated as follows

$$
P_{e l, j}=I^{2} \rho_{e l, j}^{*} \Delta z
$$

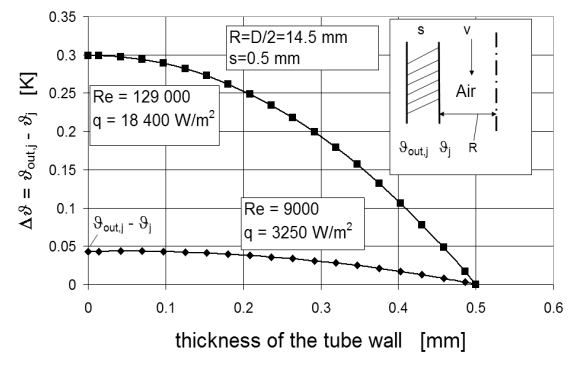

Fig. 6. Radial temperature differences 


\section{http://dx.doi.org/10.21611/qirt.2004.078}

where I is the measured current, $\rho^{*}$ el,j the specific electrical resistivity of the wall and $\Delta z$ is the length of the jth section. A calibration is made to obtain the specific electrical resistivity of the material as a function of the temperature $\rho^{*}{ }_{e l, j}=f(\vartheta)$, by measuring the current and the voltage for different temperatures.

The heat losses to the ambient in steady state are a function of the outer wall temperature, $\vartheta_{\text {out }, j}$, ambient temperature, $\vartheta_{a}$, and also of the overall heat transfer coefficient $\mathrm{k}_{\mathrm{j}}$

$$
\dot{Q}_{L, j}=\pi(D+2 s) \Delta z k_{j}\left[\vartheta_{\text {out }, j}-\vartheta_{a}\right] \text {. }
$$

Since the overall heat transfer coefficient $k_{j}$ depends on the outer wall temperature, a calibration is made by inner insulation of the tube.

The axial heat transfer rate is proportional to the difference between the axial gradients of temperature at the beginning and at the end of the discrete segment j, fig. 5 .

$$
\dot{Q}_{C, j} \approx-\pi D s \lambda_{\text {steel }}\left[\frac{\vartheta_{j+1}-\vartheta_{j}}{\Delta z}-\frac{\vartheta_{j}-\vartheta_{j-1}}{\Delta z}\right] \text {. }
$$

The sum of heat losses and axial heat conduction over the entire measuring channel length is a function of the Reynolds number. The influence of the axial heat conduction is small when compared to the electrical input power. It plays an important role only inmediately after the cross sectional change and only for a small axial distance.

\section{Experimental Results}

Fig. 7 presents the outer wall temperatures registered for turbulent air flow after a sudden contraction of the cross section at nearly constant heat flux. It can be seen that the temperature gradient is higher immediately after the change in the cross sectional area and then decreases to reach a nearly constant value. A completely different profile is observed for the sudden extension of the cross section for water, fig. 8 . In this case the temperature decreases at the beginning until a relative minimum and then increases again. This profile is a result of the eddies that appear due to the sudden increase of the cross sectional area and also indicates that the heat transfer is better in the area of low wall temperatures.

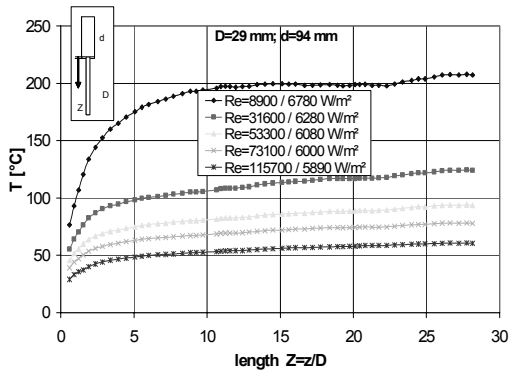

Fig. 7. Outer wall temperature for air by contraction

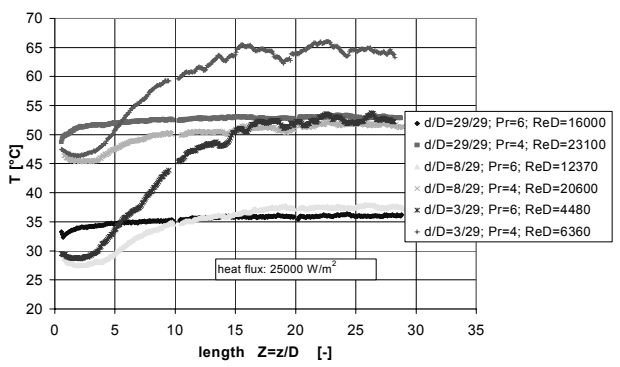

Fig. 8. Outer wall temperature for water with and without extension

If both temperature profiles for air, fig. 7, and for water, fig. 8, are compared, it can be concluded that the outer wall temperatures are in general lower for water and fluctuate more than those for air. The exact reason for these fluctuations is still being investigated. 


\section{http://dx.doi.org/10.21611/qirt.2004.078}

At this stage it is important to emphasize the advantage of the presented measuring method when compared with the use of thermocouples, which are positioned within axial distances of $100-200 \mathrm{~mm}$, [5].

The Nusselt numbers, $\mathrm{Nu}^{*}$, are valid for the heating of the working fluid. However, in order to compare them with classical correlations it is necessary to convert these values to the isothermal case. The experimental results are modified using an equation analog to that proposed by Gnielinski [6] in the case of air and the equation by Hufschmidt et al. [7] for water

$$
\mathrm{Nu}=\mathrm{Nu}^{*} /\left(\mathrm{T}_{\text {bulk, }, j} / \mathrm{T}_{\mathrm{j}}\right)^{0,45}
$$

$$
\mathrm{Nu}=\mathrm{Nu}^{*} /\left(\operatorname{Pr}\left(\mathrm{T}_{\text {bulk,j }}\right) / \operatorname{Pr}\left(\mathrm{T}_{\mathrm{j}}\right)\right)^{0,11} \text {. }
$$

The experimental error in the determination of the heat transfer coefficients depends on the measured values and can be obtained using the error propagation law. This error takes values below $5 \%$ for turbulent air flow and increases for laminar flow to more than $10 \%$. The registered errors can rise up to $15 \%$ for turbulent water flow.

A $29 \mathrm{~mm}$ diameter tube without cross sectional variation is employed to validate the measurement method. A good agreement is found over the entire developing length between the experimental Nusselt numbers and those obtained using classical correlations, [8], for both test fluids and in case of turbulent flow.

Some experimental results for turbulent air flow and a diameter ratio $d / D=8 / 29$ are represented, as an example, in fig. 9. For a cross sectional extension, the local Nusselt number, $\mathrm{Nu}_{z}$, increases until a maximum is reached, then decreases and approaches a constant value. A similar behavior is observed for other examined diameter ratios $d / D=3 / 29,16 / 29$ and $22 / 29$. The maximal values of the local heat transfer are found to range within $1<\mathrm{z} / \mathrm{D}<3$.

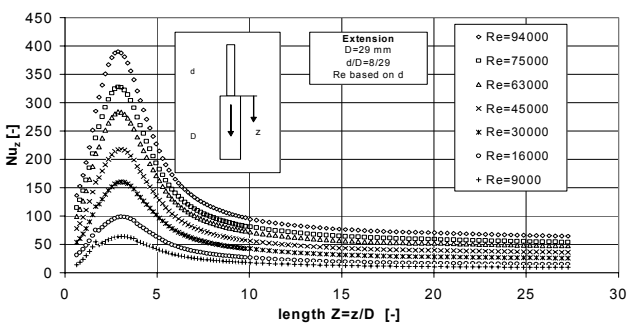

Fig. 9. Measured values of $\mathrm{Nu}_{\mathrm{z}}$ for air

The local Nusselt numbers registered for water show the same tendency as that for air, fig. 10 . In this case, the maximal value of the heat transfer is found in the range $2<d / D<3$.

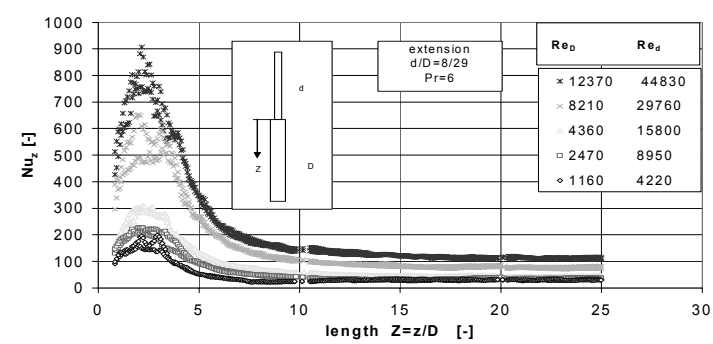

Fig. 10. Measured values of $\mathrm{Nu}_{\mathrm{z}}$ for water 
Fluctuations of the Nusselt number are detected particularly in the region where the maximum is reached. The fact that, due to the better heat transfer, the temperature difference between inner wall and water is less than $2 \mathrm{~K}$ near the maximum in some of the test series can explain these oscillations. As a result of these small temperature differences, the error in the determination of the heat transfer coefficient is higher and so variations of the Nusselt number can appear.

The high local and temporal resolution of this measurement method should be used in the future to find out the exact causes of the observed fluctuations of the Nusselt number for water.

\section{Conclusions}

The application of quantitative infrared thermography to the investigation of heat transfer characteristic is presented. The continuous and contactless measurement of the outer wall temperature distribution constitutes the basis for the determination of the heat transfer coefficients after a sudden change of the cross sectional area of a tube. Due to the high spatial resolution, variations in the heat transfer coefficients can be precisely observed and the accurate location of the maximum of the heat transfer coefficient is possible to ascertain. This is of great importance for example for the cross sectional extension.

\section{Acknowledgement}

The authors want to express their thanks to the German Research Foundation (DFG) for the promotion in the framework of the project "Measurement of local heat transfer of developing flows after cross-sectional changes using infrared thermography".

\section{REFERENCES}

[1] Hetsroni, G., Kowalewski, T. A., Hu, B., and Mosayak, A., Tracking of coherent thermal structures on a heated wall by means of infrared thermography. Exp. Fluids (2001) 30, 286-294

[2] Schmidt, J., Boye, H., Influence of Velocity and Size of the Droplets on the Heat Transfer in Spray Cooling. Chem. Eng., Technol. 24 (2001) 3, 255-260.

[3] Hapke, I., Boye, H. , Schmidt, J.: Flow boiling of water and n-heptane in micro channels. Microscale Thermophysical Engineering 6 (2002) 2, S. 99-115.

[4] Woche, H., Specht, E., Schmidt, J., Messung des lokalen Wärmeübergangs im Einlaufbereich von Rohren nach Querschnittsänderungen. Chemie Ingenieur Technik, 2002, Dez. 1711-1714

[5] Busedra, A. A., Soliman, H., M., Experimental Investigation of laminar mixed convection in an inclined semicircular duct under buoyancy assisted and opposed conditionsl. International Journal of Heat and Mass Transfer, 43 (2000) 1103-1111

[6] Gnielinski, V.: Forsch. Im Ing.-Wes. 41 (1975) Nr. 1, 8-16

[7] Hufschmidt, W., Burck, E. Der Einfluss temperaturabhängiger Stoffwerte auf den Wärmeübergang bei turbulenter Strömung von Flüssigkeiten in Rohren bei hohen Wärmestromdichten und Prandtlzahlen. Int. J. Heat Mass Transfer, 11 (1968, 1041-1048)

[8] Gnieliski, V., VDI-Wärmeatlas, 9. Auflage, 2002, Ga5, eq. (28) 